\title{
Digital Natives 3.0: Social Network Initiation
}

Francisco Amaral

Dept. of Business and Economics, University of the Azores

Rua da Mae de Deus, 9500 Ponta Delgada, Portugal

E-mail: francisco.eb.amaral@uac.pt

Josélia Fonseca (Corresponding author)

Dept. of Education, University of the Azores

Rua da Mae de Deus, 9500 Ponta Delgada, Portugal

E-mail: joselia.mr.fonseca@uac.pt

\section{Maria Tiago}

Dept. of Business and Economics, University of the Azores

Rua da Mae de Deus, 9500 Ponta Delgada, Portugal

E-mail: maria.tp.tiago@uac.pt

\section{Flavio Tiago}

Dept. of Business and Economics, University of the Azores

Rua da Mae de Deus, 9500 Ponta Delgada, Portugal

E-mail: flavio.gb.tiago@uac.pt

Received: June 21, 2016

doi:10.5296/wjbm.v2i2.9876
Accepted: July 25, 2016

Published: August 10, 2016

URL: http://dx.doi.org/10.5296/wjbm.v2i2.9876

\begin{abstract}
As generalize access to the internet becomes a reality in industrialized countries, the nature of children's social network sites (SNS) use generates concerns and requires parental different approach. The body of empirical work reviewed is still small and to develop and promote a realistic understanding of children and young adolescence behavior on online social network sites and parenting surveillance of kids' online presence, this study examines (a) who children
\end{abstract}




\section{Macrothink}

World Journal of Business and Management

ISSN 2377-4622

2016, Vol. 2, No. 2

initiate online activity and their main preferences and (b) how parental supervision techniques are applied to children's online presence. For this purpose we choose one of the most popular social network site, Facebook, and inquiry parents and kids under 13 years old (digital natives 3.0), regarding to their use. This study adds to a growing literature on young people usage of social networking technologies, specially unveiling some of the patterns of under-age kids using SNS.

Keywords: Social network, Digital native, Parenting surveillance 


\section{Introduction}

In the last decades, internet use has been the focus of several research works in different domains, reaching from psychology to business, aiming to unveil the users' behavior and drivers online. One of the sub segments that received more attention in the past is the young people, especially concerning the risks and opportunities of active internet use. In this set, only few focus on the role and impact of parents in this context and even fewer consider the last digital generation (Weeden, Cooke, \& McVey, 2013).

The virtual revolution is in full swing, reshaping parent-children relationship and children behavior, leading to question how this new generation, who never knew a world without the internet, broadband and mobile communication will cope. This work attempts to unveil the patterns of social network initiation of these children that at the time of this research were under 13, and for this reason are "illegal" users and how the parents are supervising the internet use. For this purpose data was retrieved with two different questionnaires targeting parents and their children regarding the use of the internet and parental supervision approaches.

\section{Background}

\subsection{Parent-Children Relationship on Social Network Sites}

The approach of parental supervision issues about children's access to internet and social networks raises the need to analyze and critically reflect this problem through that, conventionally, the education sciences is called education styles parental. From our point of view, and beyond the excuses that recurrently are used to explain the not parental supervision - the lack of time to be with the children and the excess of freedom that them give to offset them - there is an intrinsic relationship between the style of education that each family adopts and between the parental levels of supervision that is exercised in the various spheres of child's life, and in this area in specific.

As is traditionally classified by educational sciences, parents can have on their children in a permissive education, authoritarian and authoritative or participative (Baumrind, 1966; Vollmer \& Mobley, 2013). Permissive parents are those who do not exercise control over their children, prefer a broad autonomy of children and, therefore, don't impose to their rules or standards of conduct or encourage obedience. These parents are not active agents in changing the behavior of their children, parents are undemanding. Usually permissive parents are categorized in two ways: the indulgent, defined as those that meet the needs of their children, but are not demanding of compliance with rules and regulations on their part, not working, not shaping up as behavior models for them; negligent, are parents who do not assume their role as educators and aren't actives in the lives of children, thus demonstrating its unaccountability to the formation process of these as person (in the ethical sense of the term), these parents only worry about supply the basic needs of their children.

In fact, permissive parents care very little with the axiological and moral education of their children, consider that the control and call attention to compliance with rules and reflection on them is a way to restrict the freedom of children. Therefore, as a rule, these parents do not 
supervise their children's lives, so consistently; do not monitor access to social networks.

Contrary to these parents, authoritarian parents exert excessive control over their children, just trying to model them according to the standards and the absolute and uncompromising models of conduct they believe. The requirement is the motto of these parents who, under his aegis, completely restrict the autonomy of their children, not allowing space for communication and negotiation of rules and standards of conduct. These, as well as the values are imposed and regulated by parental authority and must be accepted uncritically by children. Noncompliance of children to parental demands leads them to the threats and punishment. In general, these are also parents who, for diametrically opposite reasons to the previous parents do not supervise the access of children to social networks because simply forbidding the access of children to them and often more radically, seal completely children's access to the net. In general, these are also parents who, for diametrically opposite reasons to the previous parents do not supervise the access of children to social networks because simply forbidding the access of children to them and often more radically, seal completely children's access to the net.

In fact, we can say that parents who have more profile to effect a conscientious and responsible supervision of children to social networks are those which fall within the authority or participative parenting style (Chng et al., 2015). These parents value the development of the autonomy of their children and therefore play an assertive control, but rational, embodied in a dialectic relationship in which both parties present arguments for their position papers: parents clearly present their ideas, giving space for the children to present the reasons for their dissatisfaction with the decisions of their parents.

This parenting style favors the conscious acceptance of moral norms and rules of conduct by children, so also create conditions so that they are active and self-reliant in the future. The exercise of discursive rationality that parents expose allows children to develop the capacity of understanding and questioning of situations / problems and favors the onset of conscious and responsible decision skills.

Usually children educated under the sign of this style know the dangers of not filtered exposure in social networks and demonstrate openness and trust in parents to speak of possible dubious situations that pose lead to violation of privacy and cyberbullying (Kiriakidis \& Kavoura, 2010).

Preventively, authoritative parents control the sites visited by their children, blocking potentially dangerous sites, visiting social networks of their children, are found in some of the moments in which they access the internet.

\subsection{The Net Generation}

The immersion in a technology-rich culture influences the skills, habits and interests of those you are born digital. Since the work of Tapscott (1998) regarding net generation, a considerable number of works have been made available about this group, its habits, competencies and behaviors. The truth is that among these researches number designation is coined to describe the young people currently studying at school, college and university. The 
common ground is the importance and significance of new information and communication technologies in these younger generations' lives. More, it's the ability to think and process information differently from their predecessors, which come from the fact that they are native speakers of a digital language (Prensky, 2001).

The generation born between 1980 and 1994 has been denominated "net generation" or "digital natives" due to their digital behavior. Using an analogy to the web evolution, the kids that were born after 1994 and before 2000 could be called to "digital natives 2.0 " since they are using not only the traditional digital tools, but are engaged in a web 2.0 environment. The conclusions of Jones et al (2009) support this distinction, since they found different patterns of adoption of ICT among the young people entering universities in 2009 compare with the previous generation. As referred by Nicholas et al. (2011, p. 29) "the «Google Generation» is a popular phrase that refers to a generation of young people, born after 1993, growing up in a world dominated by the internet and mobile devices. They have been born digital."

These young people suffer Internet exposure since their early years, which stimulated social behaviors exchanges and consequently modified their daily activities, habitats and interactions (Frand, 2000; Oblinger \& Oblinger, 2005; Prensky, 2001a, b; Tapscott, 1999). This group tends to search, to shop and live online exploring the ubiquity of the web.

Nowadays, a new generation has to be acknowledged (Holloway, Green, \& Livingstone, 2013). The sons and daughters of the digital immigrants that were born after 2001 and compose a group coined "digital natives 3.0". These children present truly high technological engagement levels and they migrated from the real to the virtual world in their early years, through games, iPods, iPads and a growing number of educational apps (Lenhart et al., 2008).

These children grown up with computers and the Internet and that gave them a natural aptitude and high skill levels when using new technologies (Weeden, Cooke, \& McVey, 2013). However, Kennedy et al. (2006) found that although young people were using a wide range of technologies in their daily lives, "there are clearly areas where the use of and familiarity with technology based tools is far from universal" (p. 8).

For more than a decade children use the Internet mainly at home and at school. Nowadays, internet use is no longer limited to a specific location and through smart phones children access internet anywhere and anytime.

Back in 2004, Livingstone and Bober (2004) reported a rigorous investigation of 9-19 years old' internet use under-going by UK Children Go Online (UKCGO). This study aimed to evaluate how the internet was transforming, or may itself be shaped by family life, peer networks and school. Their results reveal high levels of online activity by many school-aged children, mainly for homework support and social communication. But they also found that children and teenagers encounter series difficulties with evaluating search and websites contents, needing parents' guidance along the process.

Today, social communication patterns grow and new social relations are born and/or migrated to online social network. However, while learning and searching in an educational context are the main reasons for parental approval of online surfing, children and young people are more 
into technologies that allow social interaction and communication, especially social network sites (SNS)(Bennett et al., 2008; Valentine \& Hammond, 2016). This raises the interest in evaluating the social capital embedded in social network dynamics. Looking at Coleman (1988) conceptualization of social capital and its subdivisions, we will focus on family social capital. From the literature, a key component of family social capital is related to parent-child relationship in terms of parental supervision of their children's activities. As mention by Ngai et al. (2013), family social capital includes resources, time, effort, and energy parents' investment in safeguarding their children. Even though several global entities has advocated the implementation of legal safeguards designed to limit children's online disclosure (Miyazaki et al., 2009), the web traffic of young children (ages 3-12) has augmented exponentially in recent years (Weeden et al., 2013), especially in SNS (Bauman \& Tatum, 2009) and is questionable the supervision level of this presence.

In summary, and taken into account this conceptualization of parenting styles, we can frame the "digital natives" into two distinct categories: those unprotected and prospective. In the category of unprotected put children educated under the permissive and authoritarian style. If the first is unprotected because parents express an indulgent and neglectful attitude, the second is also vulnerable to the danger because they do not know nor reflect critically. Furthermore, due to excessive paternalism, they are people who are slow to be autonomous to face their problems and when they do not even know how defend themselves.

In the category of latent, we put the children educated in a participatory manner. Because they are educated in a perspective of discursive rationality that emphasizes an understanding of the situations and the mobilization of supporters arguments of their beliefs, these children, even though they may make mistakes, they are better prepared to assess and decide consciously. In fact, we believe that conditions are such that these children are citizens active, not only because they are able to solve their problems, but also because early contact, conscious and responsible to the net and social networking allows you to develop digital skills and social intervention from these.

\section{Research Framework}

With the increasing importance gave children social network use and the few studies found related to parental supervision, a deeper reflection is needed. Two research questions were formulated, with the first one primarily aiming to understand kids' preferences and parents' strategies toward social network sites use: Q1. What are the main activities conducted online by kids in social network sites? And, Q2. To what extent parents' supervision influences kids Facebook use?

Following the majors' points revealed in the literature review related to these questions and synthesize above and aiming to determine how children-parent relationship is developed in this domain the following approach was design (see, Figure 1). 


\section{NI Macrothink}

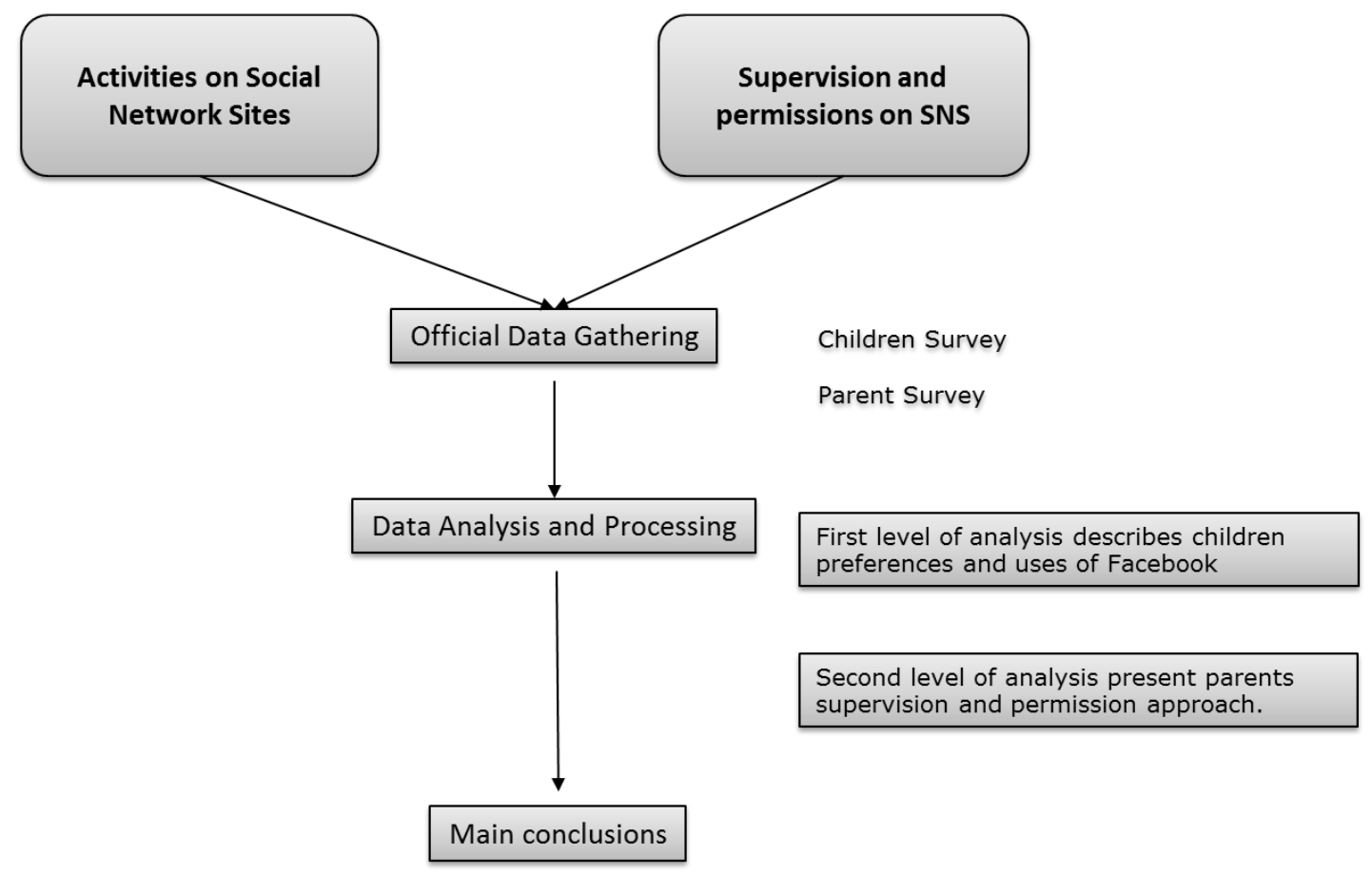

Digital Native 3.0

Figure 1. Framework design

In order to gain a full understanding of parent-preteen/children relationship, this work closely examines the key constructs of the social network, counting adults' influence and supervision on kids' enrollment in SNS. This study involved a survey design for which data were collected through a structured questionnaire. The participants were both parents and children under 13 chosen randomly. Ethical concerns were considered and parental consent was obtained after we explained the purpose of the study and the procedure to be followed; there was no obligation to participate in the study, and an assurance of confidentiality was given to all participants. In the first stage of the questionnaire was promoting online. Our questionnaire consisted of two distinctive components: the first one oriented to parents and the second to children. In the first part was composed of a number of demographic items and battery of scales concerning parent-child relationships and the use of social networking. The children component had mainly questions related to the SNS behavior and apps used. All the measures used in our study were adapted from a variety of pre-existing scales employed in the literature regarding to parents-child supervision of networking and technology usage (Mesch, 2009; Miyazaki et al., 2009; Nicholas et al., 2011; Kiriakidis \& Kavoura, 2010). The parent survey comprised a set of questions regarding children use of Facebook and parental supervision.

\section{Major Findings and Results}

Since the purpose of this paper is to develop and promote a realistic understanding of children and young adolescent behavior on online social network sites and parenting 
surveillance of kids' online presence, this study was conducted using two data samples.

The following paragraphs draw upon the survey of children, exploring reasons to use Facebook. Next table provides children with profiles, regarding age and gender. Brief notes just to remind that, all children that participate in this survey were under age (under 13 years old).

Table 1. Children profile

\begin{tabular}{|l|l|c|}
\hline \multicolumn{2}{|c|}{ Variable } & Percentage \\
\hline Age & 7 or 8 years old & 21,7 \\
\cline { 2 - 3 } & 9 or 10 years old & 34,8 \\
\cline { 2 - 3 } & 11 or 12 years old & 43,5 \\
\hline \multirow{3}{*}{ Gender } & Boys & 53,3 \\
\cline { 2 - 3 } & Girls & 46,7 \\
\hline
\end{tabular}

Table provides children with profiles, regarding age and gender. Brief notes just to remind that, all children that participate in this survey were under age (under 13 years old).

When asked about their network structure, most of the kids said that they have a network smaller than 99 people, belong these mostly to family and to school, as present in Figure 2.

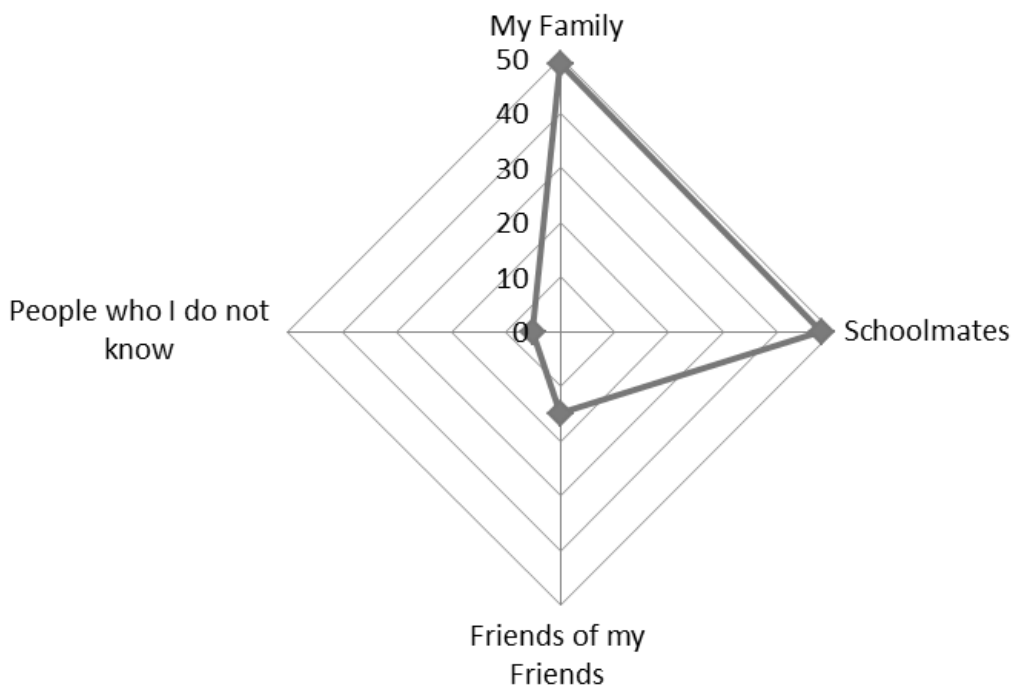

Figure 2. Kids network structure

Family are the main elements in kids' network structure, followed by schoolmates.

Performing a clustering agglomeration based on main interest online, the following chart was 
obtained regarding children activity on Facebook.

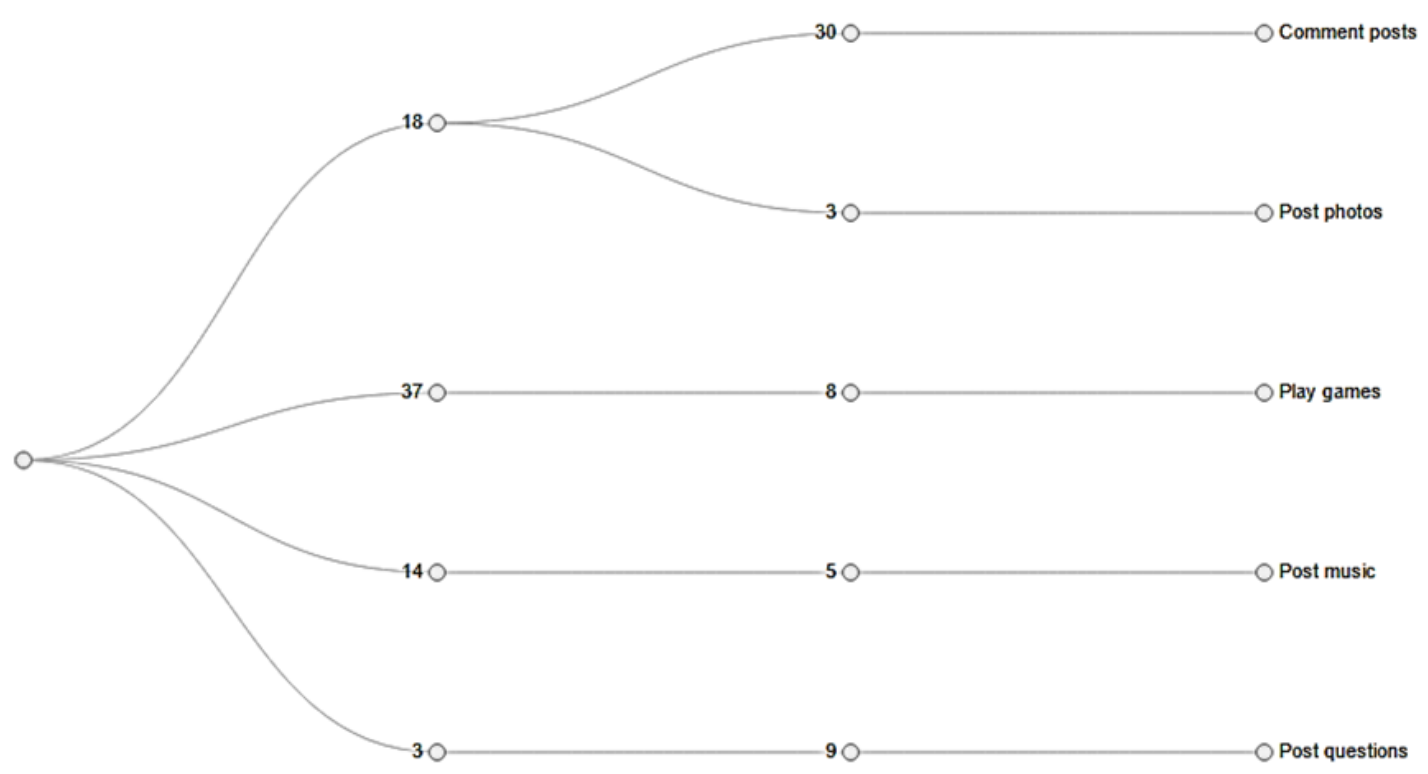

Figure 3. Activities preferentially performed on Facebook

Most children referred that their favorite activity of Facebook was playing games, followed by post and commenting photos online. The least engaging activity was posting questions to others.

When asked about the type and frequency of posting online photos, the children mostly referred that they post in a non-diary base photos (see, Figure 4):

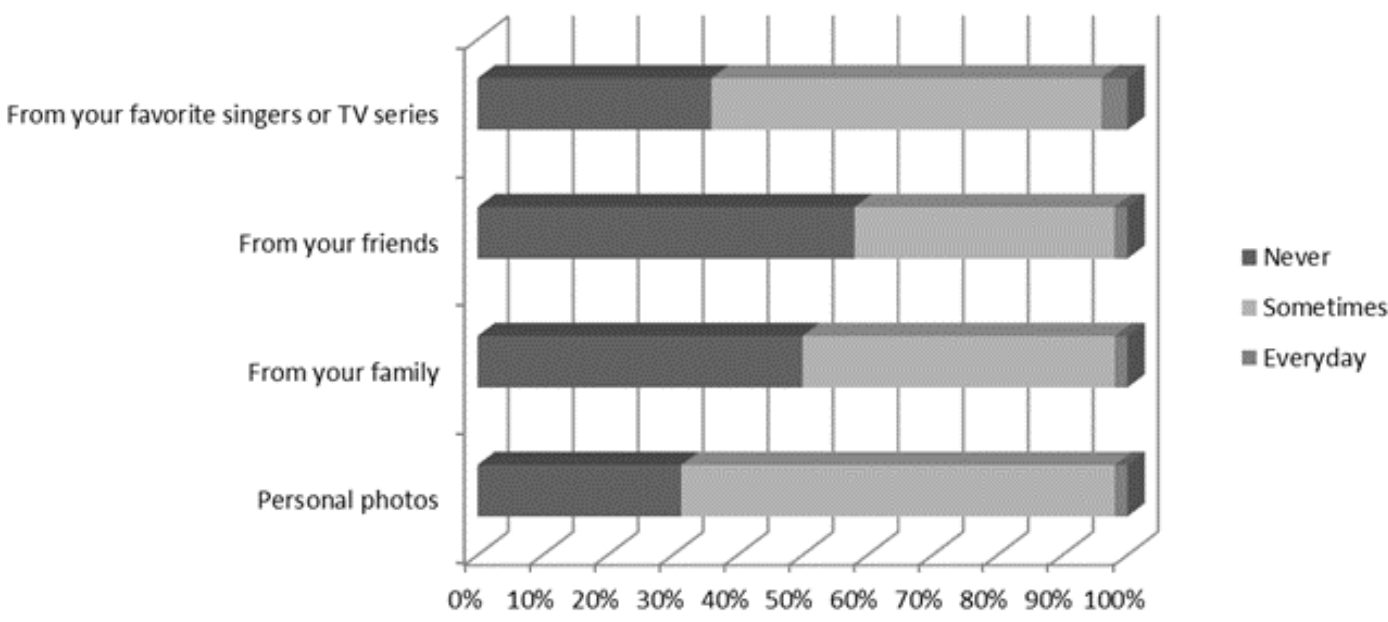

Figure 4. Types of photos post on Facebook 


\section{Macrothink}

It can be noticed that in a daily base only a few numbers of children present posting photos activity and this is more intensive (even though not relevant) in what concerns favorite singers and TV series, meaning that personal life aspect is less exposure.

Since games were the most engaging activity for the sample, we analyzed some of the Facebook most comment games and the frequency of gaming can be observed in the following figure.

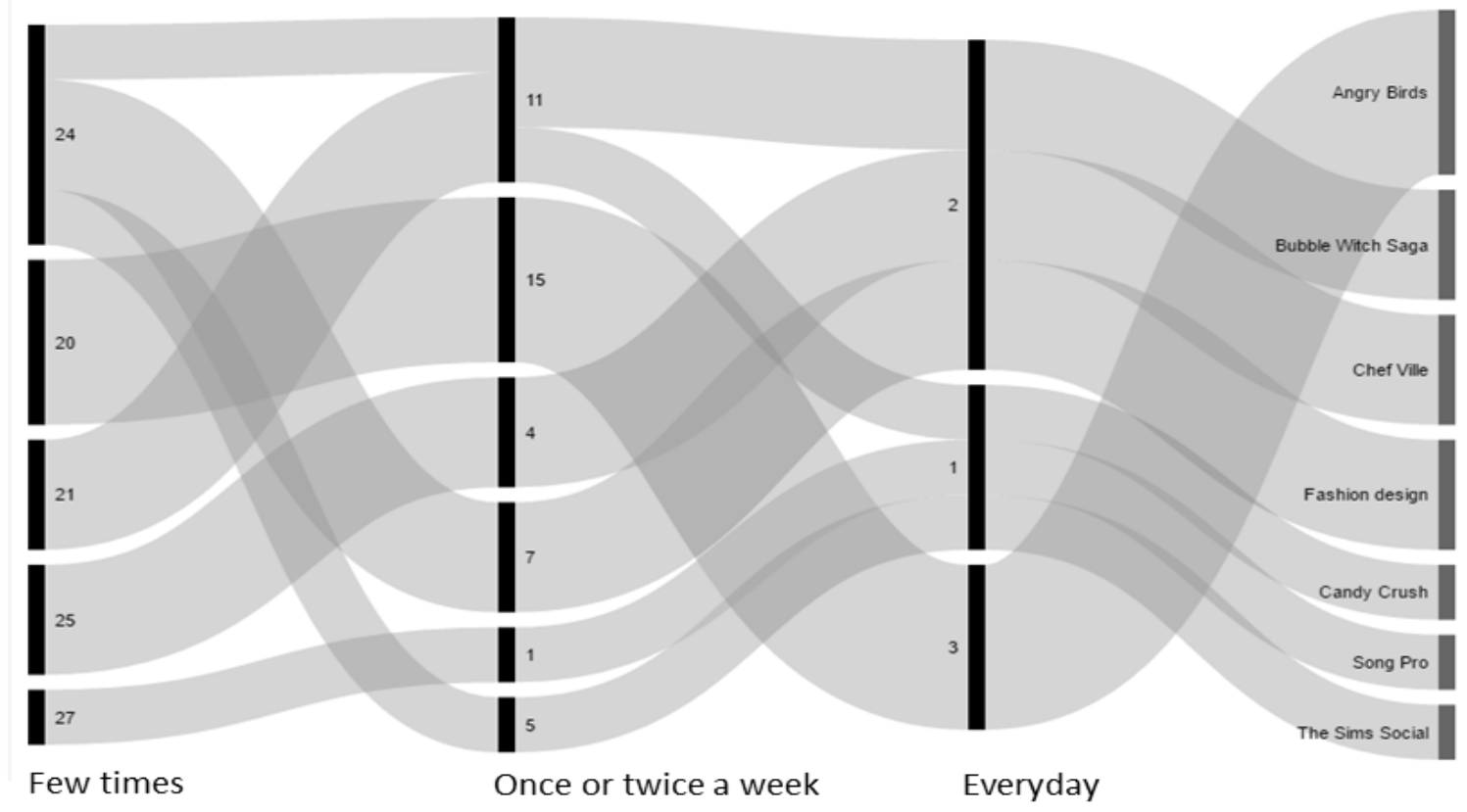

Figure 5. Types of games played on Facebook

Angry Bird was the top game played, followed by Bubble Witch Saga. Comparing these results with the highest list of games from Facebook, some interesting differences can be acknowledged. For instance, Candy Crush is not in the top 3 of preferences, while in full population has the game on the top 3 .

Knowing children preferences, it's time to analyze parents' supervision and permissions regarding children activity on social network. The survey was conducted to 137 parents, with one or more children in the target group. From the surveyed parents, 54\% referred having children using the social network site Facebook and only $7 \%$ said that their children were using parent accounts in Facebook (see, Figure 6). 


\section{Macrothink

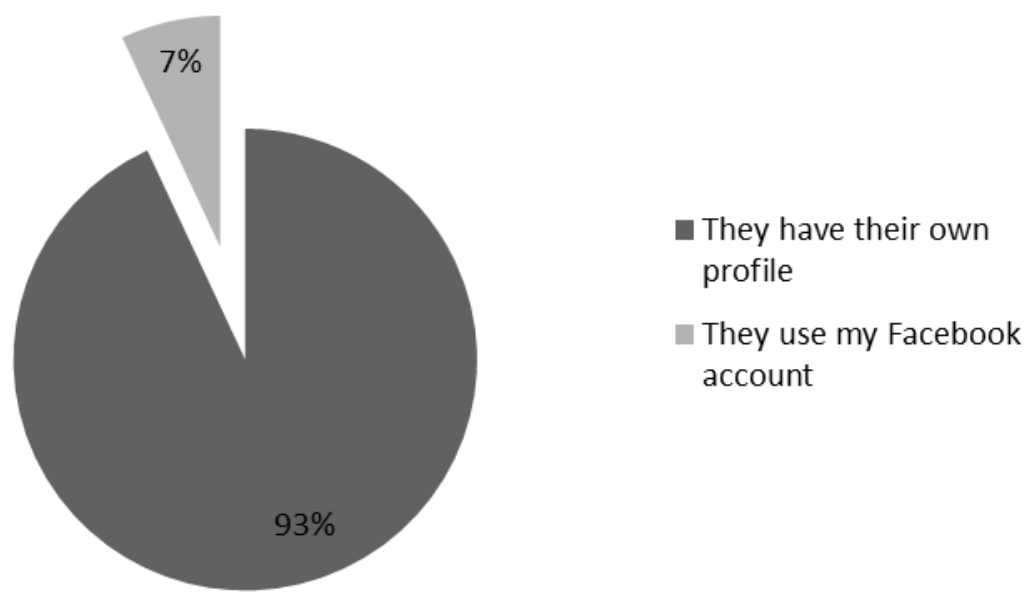

Figure 6. Facebook accounts use

Since most kids were using personal accounts, parents were asked how often they visit their kids' mural on Facebook (see, Figure 7).

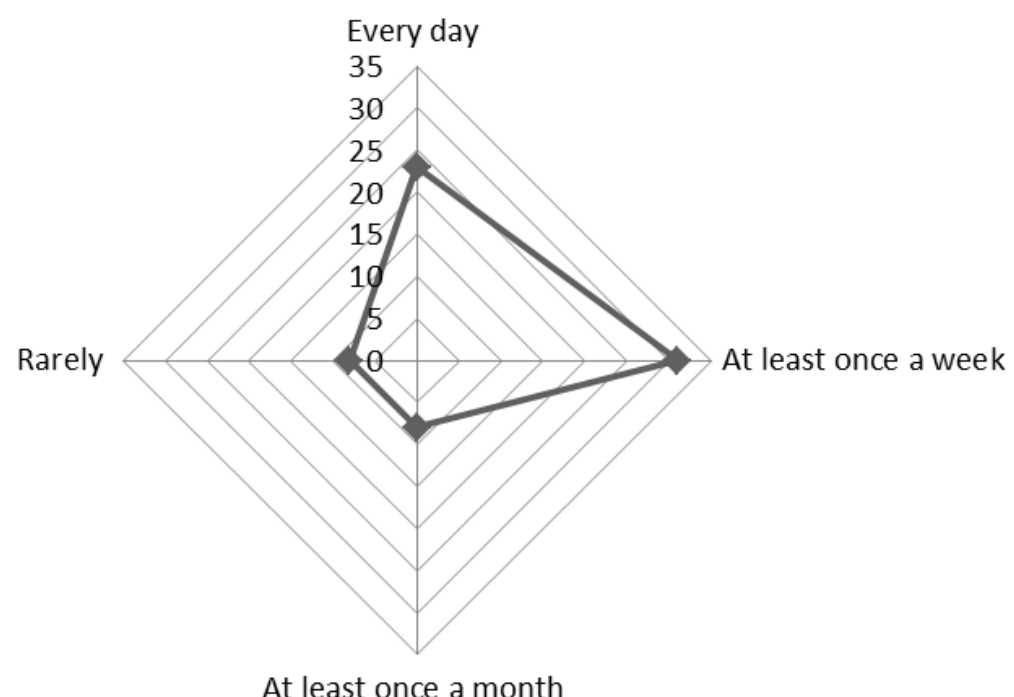

Figure 7. Parents visits to kids main Facebook page

Most parents claim to visit their kids' mural often; $33 \%$ every day and $44 \%$ at least once a mouth.

Comparing parents' perspective regarding the activities performed online with kids preferences, it can be noticed that parents perceived their kids preferences as reflection of their own and sometimes it does not correspond to kids preferences (See, Figure 8). 


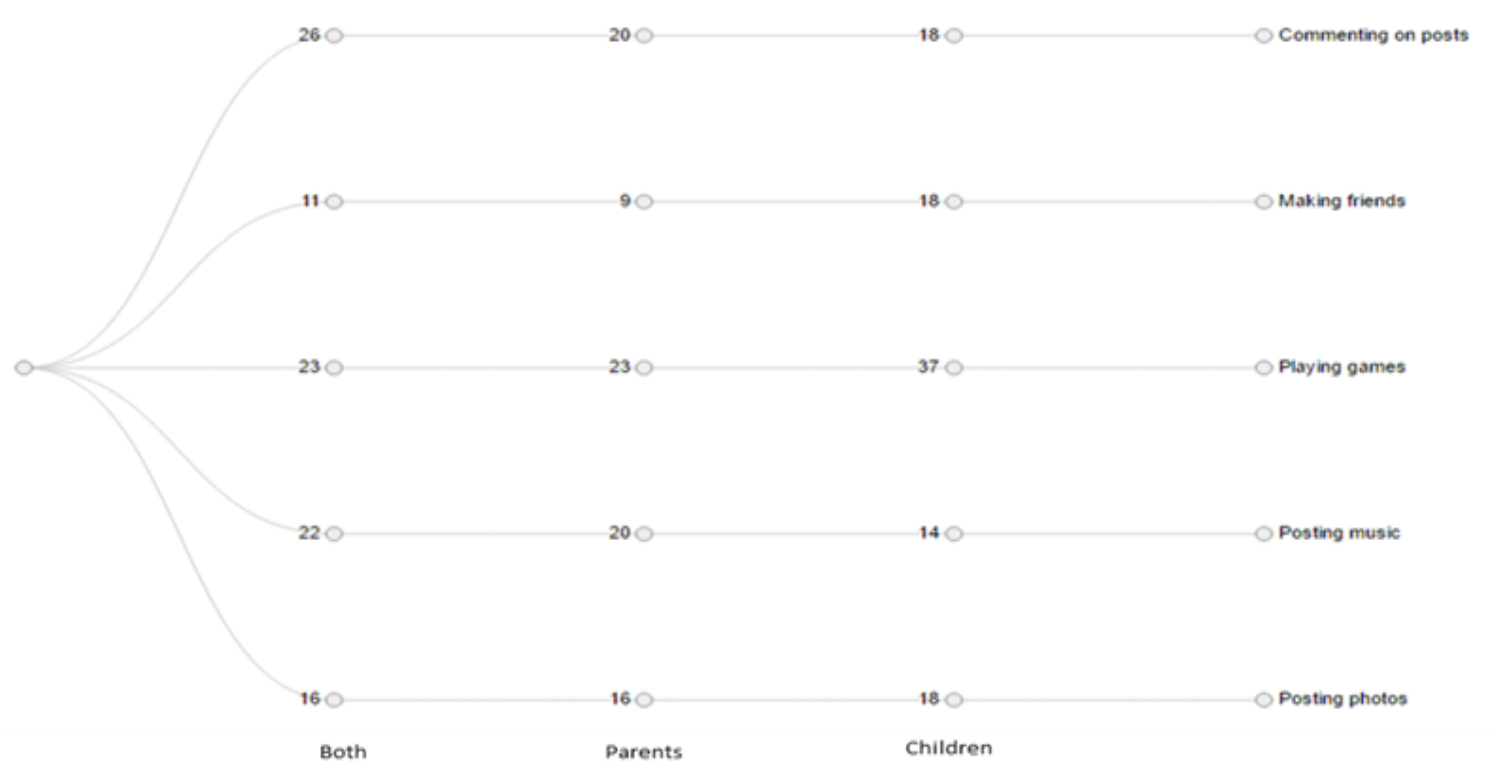

Figure 8. Parents and children activities on Facebook

As observed parents enjoy more commenting on posts and posting music, while kids prefer playing games and posting photos.

Regarding the type parental supervision, and using a scale that allows establishing the permissive and authoritarian profiles, the following results were obtained:

Table 2. Unprotected versus prospective

\begin{tabular}{|l|l|l|}
\hline Variables & Unprotected & Prospective \\
\hline Profiles usage & $98 \%$ kids own profile & $\begin{array}{l}85 \% \text { of parents } \\
\text { accounts }\end{array}$ \\
\hline Type of activities allowed & $\begin{array}{l}\text { Allow all type of } \\
\text { activities }\end{array}$ & $\begin{array}{l}\text { Only allows playing } \\
\text { games and "likes" }\end{array}$ \\
\hline $\begin{array}{l}\text { "I help my child understand what we } \\
\text { are watching on Facebook" }\end{array}$ & $\begin{array}{l}53,3 \% \text { active role; } \\
46,7 \% \text { passive role }\end{array}$ & $\begin{array}{l}74 \% \text { active role; } \\
26 \% \text { passive role }\end{array}$ \\
\hline $\begin{array}{l}\text { "When my son child is on Facebook } \\
\text { I stay with him/her just for fun" }\end{array}$ & $8,2 \%$ stay with the kid & $89 \%$ stay with the kid \\
\hline
\end{tabular}

Looking closer to the type of prohibit activities by parents within these two profiles, the following graph is obtained. 


\section{MInstitute Macrothink $_{\text {Int }}$}

World Journal of Business and Management

ISSN 2377-4622

2016, Vol. 2, No. 2

Looking closer to the type of prohibit activities by parents within these two profiles, the following graph is obtained.

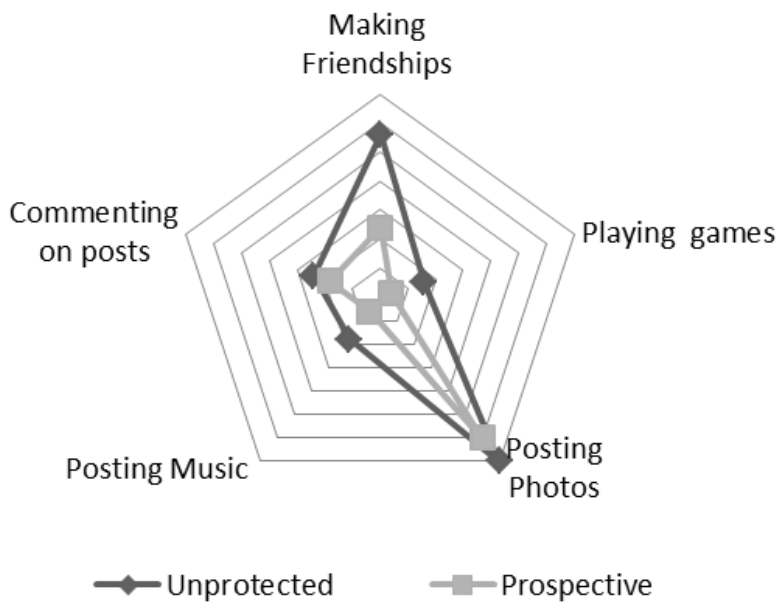

Figure 9. Activities by parent supervision profile

\section{Conclusions}

In the past years, social network sites attract an extraordinary number of users and became truly popular. Such SNS, as Facebook, change and shape the way individuals interact, collaborate and construct contents, that share and comment with friends, fans and followers. Besides this panoply of opportunities, SNS bring along new risks or transform risks that also exist in the offline world, specially to those more vulnerable, as the young people. In this sense, the Child Online Privacy Protection Act reinforces the active role of surveillance that parents should have to regard to these online activities. Acknowledging the relevance of the thematic, several academic studies focus on this subject. However, few look into the parental supervision and under-age kids' preferences and activities. With the purpose of adding to the body of research in this field, the present work is undergoing. At a first stage data was gathered using two surveys: one targeting parents and the other targeting their children under 13 years old.

The results generated some interesting findings. First, it was proven the existence of under-age kids with parents' approval on Facebook. Ninety three percent of the parents said that the kids have their own Facebook profile. This first acknowledges raising several questions regarding the approval process, surveillance and share use of Facebook by parents and their kids. More, this proves that digital behavioral construction and social networking initiation starts earlier than was supposed. This notion is important to marketers that work kids segments, because adds a new communication media to their portfolio.

The results also pointed to the notion that parenting styles are also linked to level of parental preferences, attitude and experience on social network sites use. It's also reveal that parenting 
styles differ significantly and can affect child SNS usage.

Attention should not only be paid to the children-parent relationship, but also to the tactics and strategies used by children to overcome parents' prohibition, been a path for future research works.

\section{References}

Bauman, S., \& Tatum, T. (2009). Web Sites for Young Children: Gateway to Online Social Networking? Professional School Counseling, 13(1), 1-10.

Baumrind, D. (1966). Effects of authoritative parental control on child behavior. Child Development, 887-907.

Bennett, S., Maton, K., \& Kervin, L. (2008). The 'digital natives' debate: A critical review of the evidence. British Journal of Educational Technology, 39(5), 775-786.

Chng, G. S., Li, D., Liau, A. K., \& Khoo, A. (2015). Moderating effects of the family environment for parental mediation and pathological internet use in youths. Cyberpsychology, Behavior, and Social Networking, 18(1), 30-36.

Coleman, J. S. (1988). Social capital in the creation of human capital. American Journal of Sociology, 95-120.

Frand, J. L. (2000). The information-age mindset changes in students and implications for higher education. Educause Review, 35, 14-25.

Holloway, D., Green, L., \& Livingstone, S. (2013). Zero to eight: Young children and their internet use. LSE, London: EU Kids Online

Jones, C., Ramanau, R., Cross, S., \& Healing, G. (2010). Net generation or Digital Natives: Is there a distinct new generation entering university? Computers \& Education, 54(3), 722-732.

Kennedy, G., Dalgarno, B., Bennett, S., Judd, T., Gray, K., \& Chang, R. (2008). Immigrants and natives: Investigating differences between staff and students' use of technology. Hello! Where are you in the landscape of educational technology? Proceedings Ascilite Melbourne, 2008, 484-492

Kiriakidis, S. P., \& Kavoura, A. (2010). Cyberbullying: A review of the literature on harassment through the internet and other electronic means. Family \& Community Health, $33(2), 82-93$.

Lenhart, A., Kahne, J., Middaugh, E., Macgill, A. R., Evans, C., \& Vitak, J. (2008). Teens, Video Games, and Civics: Teens. Pew Internet \& American Life Project, 76.

Livingstone, S., \& Bober, M. (2004). Taking up opportunities? Children's uses of the internet for education, communication and participation. E-Learning, 1(3), 395-419.

Mesch, G. S. (2009). Parental mediation, online activities, and cyberbullying. Cyber Psychology \& Behavior, 12(4), 387-393. 


\section{Macrothink}

Miyazaki, A. D., Stanaland, A. J. S., \& Lwin, M. O. (2009). Self-regulatory safeguards and the online privacy of preteen children. Journal of Advertising, 38(4), 79-91.

Ngai, S. S. Y., Cheung, C. K., To, S. M., Liu, Y., \& Song, H. Y. (2013). Parent-child relationships, friendship networks, and developmental outcomes of economically disadvantaged youth in Hong Kong. Children and Youth Services Review, 35(1), 91-101.

Nicholas, D., Rowlands, I., Clark, D., \& Williams, P. (2011, January). Google Generation II: web behaviour experiments with the BBC. In Aslib Proceedings, 63(1), 28-45. Emerald Group Publishing Limited.

Oblinger, D., \& Oblinger, J. (2005). Is it age or IT: First steps toward understanding the net generation. Educating the Net Generation, 2(1-2), 20.

Prensky, M. (2001). Digital natives, digital immigrants part 1. On the Horizon, 9(5), 1-6.

Tapscott, D. (1998). Wer ist die Netz-Generation? In Net Kids (pp. 35-58). Gabler Verlag.

Valentine, S., \& Hammond, T. (2016). An Analysis of Participation, Identity Conversations, and Social Networking Affordances on an Online Social Network for Children. The Journal of Media Innovations, 3(1), 41-62.

Vollmer, R. L., \& Mobley, A. R. (2013). Parenting styles, feeding styles, and their influence on child obesogenic behaviors and body weight. A review. Appetite, 71, 232-241.

Weeden, S., Cooke, B., \& McVey, M. (2013). Underage children and social networking. Journal of Research on Technology in Education, 45(3), 249-262.

\section{Copyright Disclaimer}

Copyright for this article is retained by the author(s), with first publication rights granted to the journal.

This is an open-access article distributed under the terms and conditions of the Creative Commons Attribution license (http://creativecommons.org/licenses/by/3.0/). 